\title{
Collective action to save the ancient temperate rainforest: social networks and environmental activism in Clayoquot Sound
}

\author{
David B. Tindall ${ }^{1}$ and Joanna L. Robinson ${ }^{2}$
}

\begin{abstract}
In 1993 over 850 people were arrested for engaging in civil disobedience to prevent the clear-cut logging of pristine ancient temperate rainforests in Clayoquot Sound, Canada. This was the largest incident of this type in Canadian history, and has arguably been Canada's most visible mobilization over a specific environmental issue. This study examines the factors that explain the ongoing participation of individuals in the environmental movement (more broadly, beyond participation in civil disobedience) to protect Clayoquot Sound during the period following the 1993 protest. We focus on the roles of interpersonal social networks and movement identification, and compare their statistical effects with the effects of values and attitudes on the level of participation of individuals in the movement. We compare survey data from members of Friends of Clayoquot Sound (FOCS), a key environmental organization in this protest, with data collected from several surveys of the general public, and also from members of a local countermovement group (a proforest industry group that mobilized against the environmental movement). Although values and attitudes statistically differentiate members of FOCS from the other groups, these variables do not statistically explain ongoing differential participation in the movement amongst FOCS members. Rather, individual level of participation in this environmental movement is best explained by ego-network centrality (the pattern of ties each respondent has to contacts in the movement), as measured by the number of ties FOCS members have to others in a range of environmental organizations, and by their level of identification with the movement. Implications of this research for more recent mobilizations, such as against oil pipelines, are discussed, as are avenues for future research.
\end{abstract}

Key Words: attitudes; Clayoquot Sound; countermovement; environmental activism; environmental movement; First Nations; forests; forestry; natural resources; protest; public opinion; SNA; social movement identity; social movements; social networks; values; wilderness preservation

\section{INTRODUCTION}

In British Columbia, and some other areas of North America, an important part of the environmental movement is the segment that has focused on "wilderness preservation" (Nash 2014). These mobilizations have occurred, in part, because in some areas of North America, especially in the west and north, there are significant areas of land that are relatively pristine, in contrast to many other parts of the world, in that they have not been modified through intensive logging, or other wide-scale ind ustrial activities, and have very sparse human populations. Proponents of this movement are motivated by a variety of goals, such as protecting biodiversity, animal habitat, and recreational experiences.

In 1993 over 850 people were arrested for blockading logging roads into Clayoquot Sound, an area of large relatively pristine temperate rainforests in British Columbia, Canada. The protest, sparked by the government's decision to allow logging of threequarters of the area's ancient rainforest, was the largest act of civil disobedience in Canadian history and a seminal event in the history of the environmental movement in Canada, solidifying its ability to shape environmental regulation and forest practices in the province of British Columbia. The protests, which attracted media attention around the world, were largely successful in preventing wide-scale industrial logging in the area. Why do people mobilize to protect the ancient forests of British Columbia? What factors shape their participation in this stream of the environmental movement? Using qualitative and quantitative data from a survey with members of the Friends of Clayoquot Sound (FOCS), a key environmental movement involved in the protest, we examine explanations for ongoing participation in the wilderness preservation stream of the environmental movement among members of FOCS during the period following the 1993 mass mobilization and arrests. In this paper, we employ social network analysis to explore this question regarding this intriguing case. We examine the role of social networks, socio-demographic and social psychological factors for shaping participation in the campaign to protect ancient rainforests in British Columbia.

Although the Clayoquot protest is certainly the most dramatic, and arguably one of the most important cases of environmental mobilization in Canada, most research related to this case has taken a qualitative historical approach (Wilson 1998, Cashore et al. 2000, Braun 2002, Magnusson and Shaw 2002, Berman and Leirein-Young 2011, Mabee et al. 2013). At the same time, although media outlets have conducted public opinion polling to assess public views on the case (Baldrey 1993), we provide the first scholarly quantitative examination of environmental activism in this particular movement and the factors that shape individual participation in it.

We compare survey data from members of FOCS with data collected from several surveys of the general public, and also from members of a local countermovement group. We provide an examination of the factors that shape identification with a social movement and participation in environmental protest by shedding light on the role of activists' personal networks in shaping micromobilization - the participation of individuals - in a conflict over natural resource management. 


\section{SOCIAL NETWORKS AND COLLECTIVE ACTION}

Both academic and popular understandings of participation in social movements often highlight the importance of values, beliefs, and attitudes to mobilization, and stress the idea that a person joins or supports a movement because he or she sympathizes with the cause (Dunlap 1992, Klandermans 2004). At the same time, many social movement scholars claim that although ideological orientation might be a necessary condition for social movement participation, it is not a sufficient one. For example, Klandermans and Oegema's 1987 study of the peace movement in the Netherlands found that although the vast majority of survey respondents supported the ideals of the peace movement, only a very small proportion of the population became involved in movement activities. What mattered for participation was whether individuals had ties to other movement participants, and were asked to participate through these networks. Studies on social movement networks reveal that although support for a movement's goals is a necessary condition for participation, individuals also need to be structurally linked to other members of the movement through social network ties (Tindall 2002, 2015, Diani and McAdam 2003). Key research findings on differential recruitment into social movements points to the effect of networks on individuals, stressing such factors as pre-existing ties (McAdam 1986), structural proximity of movement members (McAdam and Paulson 1993), ego-network centrality or the location of individuals within a network for explaining participation over time (Tindall 2004), and the intensity of communication within networks (Tindall 2002, Mische 2008)

Social networks comprise social units (often called nodes) that are linked together through social relationships such as friendships, acquaintanceships, or exchange relationships (Wasserman and Faust 1994). Social network scholars often examine whole networks, i.e., all of the ties that exist among a set of nodes, while others study ego-networks, the pattern of ties that exist around particular nodes. In this study we adopt an egonetwork (or egocentric network) perspective for both analytical/ theoretical reasons, and pragmatic reasons. From an analytical/ theoretical perspective, we adopt an ego-network approach because we are setting out to explain the relationship between the pattern of ties surrounding individuals and individual activism. In terms of data collection considerations, because organization lists are confidential, and because of the large size of many organizations, it is often not practical to use whole network data collection techniques such as name roster or name generator questions. Rather, we use an ego-network count technique (Marsden 2011), which is well suited for the data needs of our analytical framework.

Networks are important in social movements for coordinating collective activities (Tindall 2015), linking organizations (Andrews and Edwards 2005, Heaney and Roajs 2008, Robinson 2013), targeting individuals (Klandermans and Oegema 1987) and groups from past events to participate in new campaigns (McAdam et al. 1988), and diffusing information (Granovetter 1973, McAdam and Rucht 1993). Movement identities are also formed through social networks (Tindall et al. 2014), and new networks are a key outcome of mobilization (Diani 1997, Tindall et al. 2012). In the current study we are interested in the pattern of ties that individuals have to people in environmental organizations, and how this shapes participation in the environmental movement.

Although social networks are a consistent statistical predictor of participation they do not do anything on their own; rather social networks facilitate and/or shape various social processes. One such process is communication, which is turn is associated with the dissemination of information, social influence, the formation of trust, and the development of collective identities (Tindall 2015). At the individual level, the more connected one is to other movement participants, the more opportunities there are to communicate about movement issues. Communication is key for several processes. Information is often diffused through informal interpersonal networks. As a result of information transmitted through interpersonal networks, people may learn about issues and events they did not know about, and become more concerned about a particular issue or become more likely to attend a particular event (Tindall 2002, 2004). Social influence refers to instances where attitudes and behaviors are shaped by an individual's social ties (Friedkin 2006, Snijders et al. 2010). People may be persuaded to become concerned about an issue, or involved in an activity through their social ties. Social networks are also important as vehicles through which individuals are targeted for recruitment for participation in events (Klandermans and Oegema 1987). Finally, in some circumstances, especially where movements involve higher levels of risk and cost, networks can provide important sources of social and emotional support (McAdam 1986, Nepstad and Smith 1999).

Outside of the social movements literature, in relation to natural resources and social mobilization, scholars have pointed to the interplay between social and ecological systems. They stress the critical importance of understanding the social dimension of natural resource governance, including the key role of social networks - the interactions between diverse stakeholders such as resource users, activists and knowledge holders, institutional actors, and entrepreneurs - for generating trust and resolving conflict around natural resource management (Ernstson et al. 2010, Bodin and Prell 2011, Fisher et al. 2012, Page 2014). Scholars have pointed to the role of informal networks of individuals and organizations (versus hierarchical formal institutions) for potentially overcoming problems of commonpool resources, where responsibility is shared among a diverse array of actors (Bodin et al. 2011). The linking of diverse actors through informal networks of comanagement for example, works to establish trust and a level of mutual understanding that reduces conflict and allows for more effective resource management (Carlsson and Berkes 2005, Belaire et al. 2011, Page 2014). For example, Ernstson et al.'s (2010) study of conflict over urban ecosystem governance in Stockholm, Sweden, reveals that when government agencies and civil society groups were linked together through social networks versus formal hierarchical institutions, with key individuals acting as brokers between different groups, conflict over the management of urban ecosystems was reduced.

These studies add a critical dimension to the understanding of natural resource governance and the capacity to reduce conflict through social network linkages. At the same time, the focus of this body of research most often remains on governance structures and resource management processes. Our study focuses on social movement micromobilization to protect natural resources, which 
is critically important for shaping environmental policy (Robinson et al. 2007, Robinson 2013). We examine the importance of individual networks for explaining ongoing differential participation in social movement activities designed to shape natural resource management in Clayoquot Sound (namely, preservation of pristine temperate rainforests).

There are several challenges for research on social networks and movements. One issue is distinguishing between social influence and social selection (Snijders et al. 2010). If one forms ties with environmentalists because of her beliefs, this would be an example of social selection. However, if one is persuaded to become more concerned about environmental issues in the context of preexisting ties, this would be an example of social influence. For many phenomena both of these processes likely occur, but they are hard to untangle without longitudinal data (see Tindall 2004). We will address this issue partially through statistical control.

A second issue is the problem of sampling on the dependent variable (McAdam and Paulsen 1993). In the context of social movements, researchers often collect data on social movement participants after movement mobilization has occurred and data is limited to that collected on participants, leaving no understanding of the characteristics of nonparticipants and if or how they differ from participants. Consequently, the claim that having network ties to other participants increases the likelihood of participation in collective action would dissolve if data existed that showed that nonparticipants were equally embedded in such networks. To address this problem, we compare our survey data on members of an environmental organization with members of the general public, and members of a countermovement organization. Although this strategy has been suggested, it has not been widely explored in the social movements literature.

A third challenge, is that for larger organizations it is not practical to collect whole network data on all members (Malinick et al. 2013), and usually it is logistically difficult to obtain lists of social movement organization members. To solve this problem, we worked with an environmental nongovernmental organization (ENGO) to distribute our survey, and we developed a systematic method of collecting ego-network data (from individual actors) on ties to certain types of alters (other actors in the movement), by asking respondents to indicate people they knew from a list of key organizations.

\section{RESEARCH QUESTION AND HYPOTHESES}

Our main research question is what factors explain differential ongoing activism in the wilderness preservation stream of environmental movement (focusing on Clayoquot Sound)? We are interested in shedding light on the relative importance of socio-demographics, values and attitudes, identification, and egonetwork tie centrality for statistically explaining movement participation. Figure 1 provides an illustration of some of the theoretical relations we are considering in this study.

The central hypothesis that guides our analysis is the following:

H1. Ego-network centrality is positively associated with level of ongoing activism in the environmental movement.

We operationalize ego-network centrality (in this instance, a measure of point or degree centrality; Knoke and Yang 2008) by using number of different environmental organizations that one is tied to through interpersonal ties. (We synonymously use the term network range because this is a measure of ties to people in a range of different organizations.) For instance, if an ego knows at least one acquaintance in each of three different environmental organizations, then they would have a score of 3 for ego-network centrality. By contrast, if an individual knows three people in one organization, then they would have a score of 1 for ego-network centrality.

Fig. 1. Theoretical relations among network centrality, identification, and activism. Solid lines indicate the main direction of causality implied by the theoretical argument. Dashed lines indicate acknowledged feedback loops.

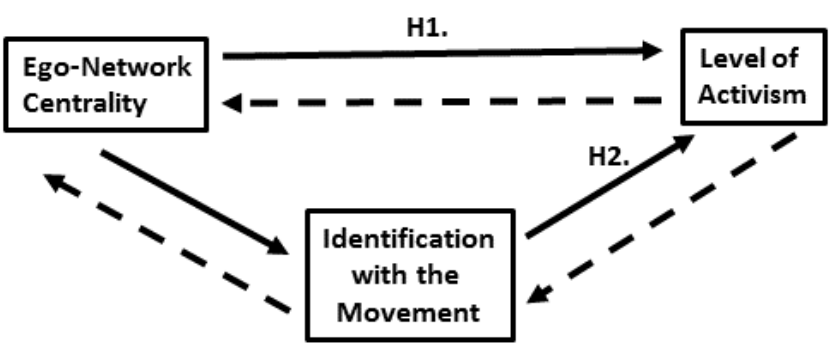

In this article we use the term "ongoing activism" to indicate that we are considering participation in activities over a period of time, not just participation in a single event. Also, it is worth highlighting, that even though the data collection was crosssectional, our measure of activism (described in detail later) is based on participation in a variety of activities over time. Thus, for level of ongoing activism, we are referring to ongoing activism over time in a variety of different low to medium cost environmental movement activities (cost here meaning the amount of time and effort one needs to put in to be involved in these kinds of movements). These activities are not specific to any given organization.

Our secondary hypothesis is the following:

H2. Level of identification with the environmental movement is positively associated with level of ongoing activism.

In part, collective identities provide normative expectations about action. People are motivated to participate in environmental movement activities to validate a valued identity, such as being a member of the environmental movement (McAdam and Paulsen 1993, Snow and McAdam 2000). We refer to this as a secondary hypothesis, because $\mathrm{H} 1$ is most central to our theoretical focus in this article.

Figure 1 displays proposed theoretical relations among network centrality, identification, and level of activism. Of course, egonetwork centrality and identification are not the only variables of potential relevance for explaining differential activism. Our goal is not to develop a complete explanatory model for explaining activism, but rather to test the potential effects of networks on activism while controlling for other key variables, in order to rule out the possibility of findings being due to spurious effects.

The solid lines in Figure 1, indicate the direction of theoretical causality that we emphasize. For instance, we conjecture that the more embedded in the movement one is through her ego-network, 
the more active she will become. This is partly due to increased communication, information, and social influence (Kitts 2000, Passy 2001). Also, the more strongly one identifies with the movement, the more active she will become, because identity provides a motivation for action (McAdam and Paulsen 1993).

Theoretically, we would also expect ego-network embeddedness to be associated with level of identification (Tindall 2002, 2004). For example, greater ego-network centrality provides a greater array of alters (those whom one is tied to) with whom to make social comparisons (Gartrell 1987), and positive social comparisons with other members of the environmental movement will shape and reinforce one's own identity as an environmentalist. However, formally exploring this part of the theoretical model is beyond the scope of the present analysis.

We would also expect there to be reciprocal causal effects among all of these pairs of variables. These expectations are indicated by the dashed lines in Figure 1. Although people with greater network centrality would be expected to be more active, conversely, the more active one is, the more opportunities there are to form social ties with other members of the environmental movement. As noted above, the more strongly one identifies with the movement the more active they will be. At the same time, as suggested by self-perception theory (Bem 1972), some people will become involved in environmental movement activities for various other reasons such as receiving a request to participate from a friend (see also Gould 2003), and will subsequently identify themselves as a member of the environmental movement as a consequence of their behavior. Finally, although we would expect people with more ties to people in the environmental movement to identify more strongly as a member of the movement, we would also expect that those who identify as part of the movement to be more likely to form new social ties with other members of the movement.

Because we are utilizing cross-sectional data (Babbie and Benaquisto 2010), we cannot readily examine reciprocal causation. The solid lines associated with $\mathrm{H} 1$ and $\mathrm{H} 2$, consistent with theoretical arguments reported in the literature (Tindall 2015), illustrate our main theoretical focus. However, because we are utilizing cross-sectional data, we can only test whether there is correlational evidence for the hypothesized relations. We explore these general hypotheses in the context of the case of ongoing social movement activity regarding the forests of Clayoquot Sound.

\section{METHODS}

The data of primary focus for this study consists of quantitative survey data from a probability survey of members of Friends of Clayoquot Sound, an environmental organization based in Tofino, British Columbia, whose members were heavily involved in the 1993 protests in Clayoquot Sound. These data are supplemented with qualitative data from written responses to open-ended questions to the FOCS questionnaire, and with some additional interviews with movement participants. In addition, we conducted three additional surveys for comparative purposes. The quantitative data reported here were collected in the late 1990s and the first half of the 2000s as separate data collection initiatives in the context of a larger program of research on environmentalism in British Columbia and Canada.
Friends of Clayoquot Sound survey

The Friends of Clayoquot Sound (FOCS) was established in 1979 in Tofino, British Columbia as a grassroots, community-based organization dedicated to protecting the Clayoquot Sound region and stopping industrial logging through direct action and advocacy. It formed in response to the forest industry's plan to clear-cut log Meares Island, near Tofino. The plan sparked widespread opposition from the local community who valued the island for its beauty, and as the local source of water. Because the island is also a First Nation's spiritual base, it also provided a strong alliance of purpose between First Nations and FOCS environmentalists (Robinson et al. 2007).

\section{Data collection and sampling}

The primary data gathering procedure was a self-administered questionnaire sent to all of the members on the FOCS mailing list who reside in British Columbia (e.g., a census of FOCS members) in 2005. In total, 211 completed questionnaires were returned for a response rate of $54.2 \%$ percent. Relative to similar types of research this is quite a good response rate. The survey was designed to shed light on the reasons why people participate in the wilderness preservation movement on Vancouver Island in particular, and the environmental movement in general.

In terms of the characteristics of the respondents to this survey, participants were "rank and file" members of FOCS. In other words our survey is not focused just on core members or leaders, but rather is a representative sample of the general membership. In terms of potential response biases, past survey researchers have found that people who feel very strongly about an issue, or have more flexible time, tend to be more likely to respond to surveys. In the case of the present survey, results show a normal distribution for participation in the movement. So it is not the case that respondents to this survey were mostly highly active people. Rather, the average survey respondent was moderately active. Compared to other surveys we have conducted on this topic with similar populations, the average respondent was somewhat older, and slightly more likely to be a woman, though it is possible that these characteristics are representative of FOCS. At the same time, there was substantial variation on all variables so these tendencies should not affect the results of correlational hypotheses (Opp 1986). Also, it should be noted that we statistically controlled for gender and age in the ordinary least squares (OLS) multiple regression analyses.

Although the response rate is quite good compared to similar studies, it is still possible there is some sampling bias associated with nonresponders. To examine this possibility we conducted an analysis comparing late responders with early responders (Moore and Tarnai 2002, Groves 2006). The analytical inference from this type of analysis is that late responders are more similar to nonresponders. We conducted t-tests, comparing late responders with early responders for level of activism, and for all of the variables included in the comparative analysis (attitudes about job loss due to clear-cutting, postmaterialist values, range of network ties, movement identification, and activism). There were no significant differences for these variables between early and late responders. Thus, we did not observe any obvious sources of sampling bias. Also, to reiterate, even some degree of sampling bias should not affect results concerning correlational hypotheses (Opp 1986). 
Table 1. List of activities used to construct the level of activism index.

1. Donated money to a wilderness conservation or other environmental organization. $(\mathrm{W}=1)$

2. Written a letter to a government official regarding a wilderness conservation issue (such as conservation of the Carmanah, Walbran, or Clayoqout). $(\mathrm{W}=2)^{\dagger}$

3.Sent a letter (fax or e-mail) to a newspaper about wilderness conservation (or forestry related issues). $(\mathrm{W}=2)^{\dagger}$

4. Sent a letter (fax, e-mail, phoned) to a logging company about a forestry (or wilderness) issue. $(\mathrm{W}=2)^{\dagger}$

5. Sent a letter (fax, e-mail, phoned) to another organization regarding a wilderness conservation issue. $(\mathrm{W}=2)^{\dagger}$

6. Signed a petition to conserve a wilderness area. $(\mathrm{W}=1)^{\dagger}$

7. Participated in trail building. $(\mathrm{W}=4)$

8. Attended a community meeting about wilderness conservation and/or forestry. $(\mathrm{W}=2)^{\dagger}$

9. Attended a rally or protest demonstration on the lawns of the legislature to support wilderness conservation. $(\mathrm{W}=2)^{\dagger}$

10. Participated in an information campaign for the general public about wilderness conservation. $(\mathrm{W}=3)$

11. Advertised in the media to promote wilderness conservation. $(\mathrm{W}=3)$

12. Made a presentation to a public body about wilderness conservation and/or forestry-related issues. $(\mathrm{W}=3)$

13. Given a lecture on wilderness conservation and/or logging practices to a school group or voluntary organization. $(\mathrm{W}=3)$

14. Participated in a press release or press conference (regarding wilderness conservation and forestry-related issues). ( $W=3$ )

15. Served as a representative on an advisory board formed around wilderness conservation or forestry-related issues $(\mathrm{W}=4){ }^{\dagger}$

16. Purchased a book, t-shirt, poster, mug, or other merchandise from an environmental organization. $(\mathrm{W}=1)^{\dagger}$

17. Boycotted a product or company because of environmental concern. $(\mathrm{W}=1)$

18. Worked to elect someone because of their views on the environment. $(\mathrm{W}=4)$

19. Voted for someone because of their environmental views. $(\mathrm{W}=1)^{\dagger}$

20. Any other activities (that you have done to help conserve wilderness?) $(\mathrm{W}=2.5)$

Indicates item included in Activism Short Index for comparison.

Letter writing items $(2,3,4$, and 5) were collapsed into a single category for inclusions in the weighted Level of Activism Index; if any letter writing items were recorded the respondent received a maximum weight of 2 for letter writing.

$\mathrm{W}$ indicates weight given to item.

\section{General public surveys, countermovement survey}

\section{Data Collection and Sampling.}

Data come from (1) a telephone interview survey with a random sample of the Greater Victoria general public in 1999 and 2000 $(\mathrm{N}=150)$; (2) a telephone interview survey with a random sample of the Port Alberni general public in 1998 and $1999(\mathrm{~N}=100)$; (3) a self-administered questionnaire distributed to a random sample of members of "Share Our Resources" in 1999 and 2000 (an antienvironmentalism countermovement organization) in Port Alberni $(\mathrm{N}=129)$. These surveys generally contained the same items as were included in the FOCS survey, but for the general public samples only subsets of items were included, e.g., postmaterialist values, activism. More details are available upon request by contacting the first author.

\section{Measures: Friends of Clayoquot Sound survey}

\section{Activism}

The main dependent variable is level of ongoing activism. This was constructed from responses to a set of 20 items, about different types of participation in the environmental movement, not specific to FOCS, including things like attending a protest rally, signing a petition, writing a letter, giving a lecture to a school, attending a community meeting (the full list of items is provided in Table 1.)

These were drawn from Tindall (2002), and were subsequently refined. It should be noted that, partly for ethical reasons, the items comprised low- to medium-cost, legal activities. Initial analysis provided strong justification for construction of a single measure of level of activism. Reliability analysis (Carmines and Zeller 1979) of the items revealed a Chronbach's $\alpha=0.87$. Principal component analysis (Kim and Mueller 1978) provided support for constructing a single factor because there was a large drop off between component 1 and 2. All loadings were 0.3 or higher. Though it might be noted that it would be possible to construct a single measure as we have done here, or several measures grouped by the amount of time involved in the activities. Subsequent to the above analyses, several measures of letter writing were grouped into a single indicator. Finally, all indicators were weighted based on the amount of time required for each activity, and summed. See Tindall (2002) for details regarding an earlier study. The end result is an interval-ratio measure of activism. This variable is approximately normally distributed. A higher score means that an individual was more active, a lower score means they were less active.

\section{Range of ENGO ties}

Respondents were provided with a list of 10 environmental organizations, and asked for each one whether they knew a member of the group. Responses were coded 0 or 1 and then summed. The higher the score, the greater the range of environmental organizations where an individual knew a member. This is the operationalization of ego-network centrality.

\section{Perception of overcutting}

Respondents were asked to indicate on a five point scale whether or not they agreed with the statement: "Most jobs in the forest industry have been lost because of a reduced timber supply due to over-cutting." This item is used as an attitudinal measure of concern about overcutting.

\section{Postmaterialist values}

Respondents were asked to rate the importance of a series of materialist and postmaterialist values, as defined by Inglehart (1977), such as valuing the importance of "people have more say in how things get decided at work and in their communities" over "maintaining a high rate of economic growth." This is a modified 
Table 2. Comparisons of Friends of Clayoquot Sound sample with the Victoria general public, Port Alberni general public, and Share our Resources countermovement organization members. (Significance for cross-classification percentage tables based on chi-square tests, significance for difference in means based on $\mathrm{F}$ tests.)

\begin{tabular}{|c|c|c|c|c|c|}
\hline & $\begin{array}{c}\text { Share } \\
\text { Counter } \\
\text { Movement }\end{array}$ & $\begin{array}{l}\text { Port Alberni } \\
\text { General } \\
\text { Public }\end{array}$ & $\begin{array}{l}\text { Victoria } \\
\text { General } \\
\text { Public }\end{array}$ & $\begin{array}{c}\text { FOCS } \\
\text { Members }\end{array}$ & Sig. \\
\hline$\%$ Mostly/completely agree job loss due to overcutting & $5.5 \%$ & $22.6 \%$ & $39.5 \%$ & $48.7 \%$ & $* * * *$ \\
\hline$\%$ Very strongly/strongly agree ... identify with environmental movement & $5.6 \%$ & $4.3 \%$ & $10.8 \%$ & $78.2 \%$ & $* * * *$ \\
\hline PMV Short Index: Mean & 3.26 & 2.60 & 2.74 & 2.10 & $* * * *$ \\
\hline PMV Short Index: SD & $(1.37)$ & $(1.48)$ & $(1.27)$ & $(1.26)$ & \\
\hline Range of ENGO Ties: Mean & 0.85 & 0.57 & 0.77 & 1.31 & $* * * *$ \\
\hline Range of ENGO Ties: SD & $(1.61)$ & $(1.22)$ & $(1.27)$ & $(1.74)$ & \\
\hline Activism Short Index: Mean & N.A. & 2.38 & 2.37 & 5.80 & $* * * *$ \\
\hline Activism Short Index: SD & N.A. & $(2.18)$ & (1.89) & (1.63) & \\
\hline
\end{tabular}

$* \mathrm{p} \leq 0.05,{ }^{* *} \mathrm{p} \leq 0.01,{ }^{* * *} \mathrm{p} \leq 0.005,{ }^{* * * *} \mathrm{p} \leq 0.001$

$\mathrm{ENGO}=$ environmental nongovernmental organization

$\mathrm{PMV}=$ postmaterialist values

version of the scale developed by Inglehart (1977). We summed together the responses to seven postmaterialist items (using a 10 point scale) and constructed an index ( $\alpha=0.85$ for these items). Low scores indicate relative support for postmaterialist values. High scores indicate lack of support for postmaterialist values.

\section{Identification with the environmental movement}

Respondents were asked to indicate on a five point scale whether or not they agreed with the statement: "I identify myself as a member of the environmental movement."

\section{Control variables}

Data were also obtained for "years of education," "personal annual income in dollars," "gender" (female =1), years of "age," and "length (years) of membership" with FOCS. More details on these variables are available upon request.

\section{Frequency of communication}

Respondents were asked to indicate from a set of categories how often they talked with others about environmental issues. Responses were then transformed into an estimate of the number of days per year they communicated about environmental issues.

\section{Frequency of being targeted with requests to participate}

Respondents were asked to indicate from a set of categories how often they received requests to participate in (nonorganization specific) environmental movement activities. Responses were then transformed into an estimate of the number of days per year they received requests to participate.

\section{Measures: secondary studies}

For the secondary studies, the measures of attitudes about overcutting, identification with the environmental movement, and range of network ties are identical to above. The postmaterialist values index, and activism index used subsets of items. For the analyses in Table 2, the measures for FOCS were adjusted to make them comparable. For the comparisons, the activism index is based on an unweighted count of items the respondent has participated in. This is to make the comparisons easier to interpret.

\section{Missing values}

For the FOCS sample, missing data in the form of nonresponses existed for small proportions of cases for the variables included in the forthcoming analyses. The SPSS multiple imputation procedure was undertaken to impute missing values (IBM Software Group 2016).

\section{Data analysis}

All statistical analyses reported in this article were computed using IBM SPSS Statistics Version 24 (IBM Corp 2016). Basic bivariate analyses were conducted to describe intergroup comparisons. (See Table 2.) The statistical analyses included percentages, or means, and standard deviations are reported (depending upon the variable). Chi-Square (for percentages), and ANOVA (for means) analyses were undertaken to conduct tests of significance of differences between groups. For the three comparison groups, only respondents who did not belong to an environmental organization are included in the analysis, so we can compare environmental organization members with nonenvironmental organization members.

For the multivariate analysis, OLS multiple regression was employed (Fox 1997; see Table 3.) The dependent variable is level of participation in environmental movement activities. The first column of data in Table 3 provides standardized regression coefficients for the original data. Models with multiple imputation (IBM Software Group 2016) for missing data were also estimated, and minimum coefficient values are listed in column 2, and maximum values in column 3 . In column 4 , pooled significance values are provided.

In Table 4, several bivariate Pearson's correlation coefficients are calculated to describe the associations between the dependent variable (level of activism), the main independent variables (range of ENGO ties, and level of environmental movement identification) with two variables thought to be important for interpersonal interaction in social movement mobilization (frequency of communication, frequency of receiving recruitment requests). 
Table 3. Ordinary least squares multiple regression analysis explaining level of activism in the environmental movement using standardized regression coefficients.

\begin{tabular}{|c|c|c|c|c|}
\hline & Original Data & Min. & Max. & Pooled sig \\
\hline Education & -0.023 & -0.008 & 0.038 & \\
\hline Income & -0.084 & -0.083 & -0.135 & \\
\hline Gender $($ Female $=1)$ & -0.119 & -0.210 & -0.222 & $* * * *$ \\
\hline Age & $-0.166^{*}$ & -0.142 & -0.193 & * \\
\hline Postmaterialist Values Index & -0.020 & 0.006 & 0.021 & \\
\hline Overcutting (has led to job loss) & $0.159^{*}$ & 0.096 & 0.124 & \\
\hline Range of ENGO Ties & $0.320 * * *$ & 0.286 & 0.318 & $* * * *$ \\
\hline Identification & $0.197 *$ & 0.158 & 0.196 & $* * *$ \\
\hline Length of Membership & $0.286^{* * *}$ & 0.295 & 0.356 & $* * * *$ \\
\hline $\mathrm{R}^{2}$ & $0.373^{* * *}$ & 0.331 & 0.370 & $* * *$ \\
\hline Adjusted $\mathrm{R}^{2}$ & $0.322 * * *$ & 0.301 & 0.342 & $* * *$ \\
\hline $\mathrm{N}$ & 122 & 210 & 210 & \\
\hline
\end{tabular}

$* \mathrm{p} \leq 0.05,{ }^{* *} \mathrm{p} \leq 0.01,{ }^{* * *} \mathrm{p} \leq 0.005,{ }^{* * * *} \mathrm{p} \leq 0.001$

$\mathrm{ENGO}=$ environmental nongovernmental organization

\section{RESULTS}

We begin our analysis by describing the context of the study and presenting some of the qualitative findings to illustrate the meanings that people ascribed to their participation in the movement.

\section{The struggle to protect Clayoquot Sound}

Clayoquot Sound, on the west coast of Vancouver Island in British Columbia Canada, covers approximately 350,000 hectares, and comprises remote islands, fjords, watersheds, and the largest nearly intact temperate rainforest ecosystem on Vancouver Island. As home to endangered ancient rainforests, it is considered by many to be a priceless natural heritage. Figure 2 provides a map of Vancouver Island, and provides details on the location of Clayoquot Sound.

Fig. 2. Map of Vancouver Island.

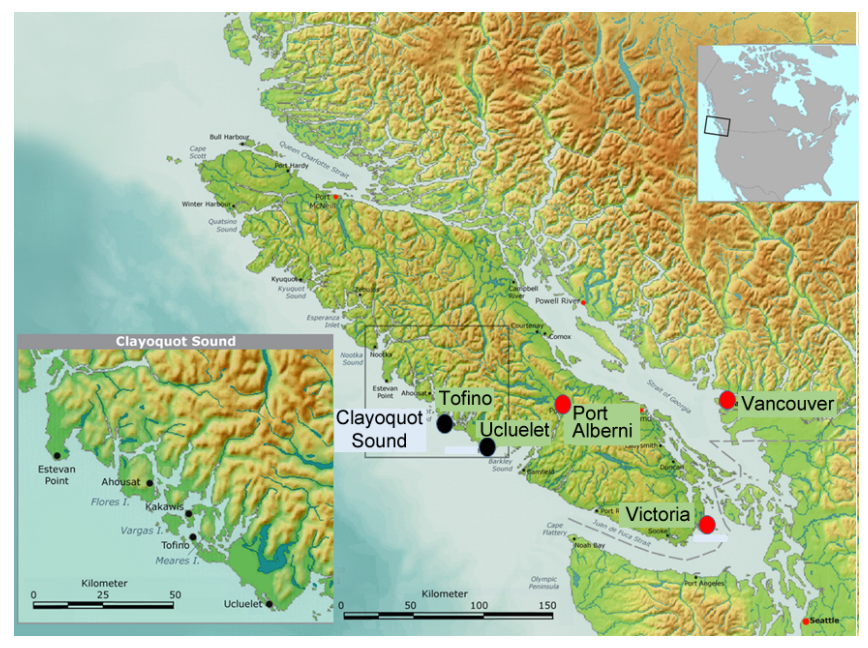

The Clayoquot Sound region is also home to the Nuu-chah-nulth First Nations. There are 15 Nuu-chah-nulth, of which three central regional groups, the Hesquiat, Ahousat, and Tla-o-quiaht First Nations, are within the Clayoquot Sound region. The region also includes the non-Aboriginal community of Tofino, while the non-Aboriginal communities of Ucluelet and Port Alberni are also in very close proximity, and are intricately bound up in the economics, culture, and politics of the region.

The geography and political economy of the region provide an important context for understanding environmental conflict in the region. The FOCS are headquartered in Tofino, in the Clayoquot Sound area, though the organization has members and supporters spread throughout Vancouver Island and the rest of the province. Tofino is a popular tourist destination, and many thousands of people drive to this destination every year. The capital of the province of British Columbia, Victoria, is a medium sized city on the southeast tip of Vancouver Island with an economy largely based on the public sector and service sector. The main access to Tofino is via a highway that passes through Port Alberni, a natural resource-based community, which has historically relied on forestry and fishing for its economic base. In times of conflict over forestry, many environmentalists and nature lovers passed through the forestry-town of Port Alberni on their way to Clayoquot Sound.

In the early 1990s a conflict arose over the logging of pristine rainforests in Clayoquot Sound, one of the few remaining intact old-growth, temperate rainforests in British Columbia, and the world more generally. Environmental groups employed different tactics to raise awareness of the issues, sway public opinion, and influence government decision makers, including giving public presentations, producing information brochures, coffee table books, and videos, protesting on the lawns of the provincial legislature, and blockading logging road in the vicinity of Clayoquot Sound. The campaign culminated with a mass protest in 1993 after the provincial government announced plans to open up two-thirds of the Sound to extensive logging, where over 850 people were arrested for engaging in civil disobedience by blockading logging roads leading into the Clayoquot Sound (Tindall 2013). Campaigns involving various tactics (including protests) have continued, though these have been somewhat episodic, and the protest unquestionably reached its zenith in 1993. We examine ongoing activism in this movement.

Although no permanent measures have been enshrined to protect the area, no large-scale industrial logging has since taken place in 
Table 4. Correlations of interpersonal interaction variables with key independent and dependent variables.

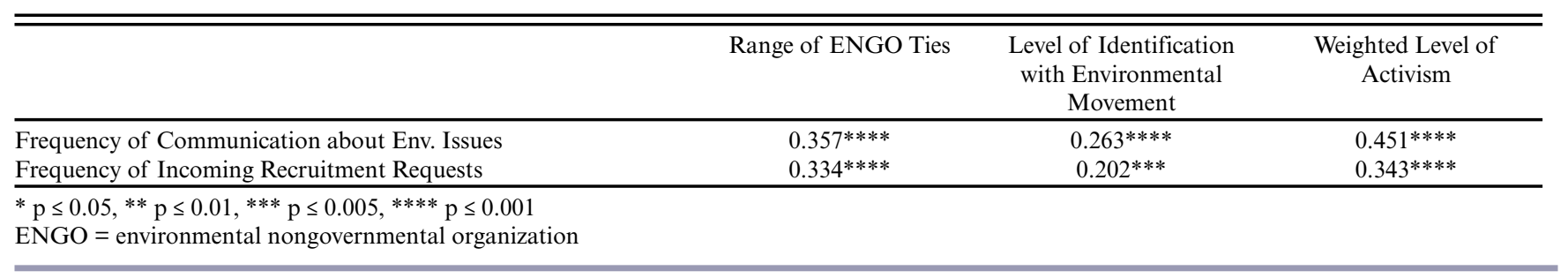

the region, likely a result, at least partly, of the wide-scale protest. Key outcomes include a government-ordered moratorium on clear-cut logging and the creation of a scientific panel to study uses for the area. An interim measures agreement was later signed, initiating comanagement between First Nations and the provincial government and resulting in provisional protection of the Clayoquot Sound area (Shaw 2002, Mabee et al. 2013). In the context of these dynamics, an alliance of environmental organizations supported the creation of a First Nations-owned forestry company to undertake small-scale sustainable logging, and to engage in other sustainable uses of the forest (Robinson et al. 2007, Pechlaner and Tindall 2013). In 2000 Clayoquot Sound was designated a biosphere reserve by UNESCO. In October 2015, the Ahousaht Hereditary Chiefs announced a moratorium on industrial logging on their territory in Clayoquot Sound. The rich political, economic, and environmental history of the Clayoquot Sound region, including its relatively pristine natural setting and site for conflict over natural resource management makes it a key case for understanding the dynamics of environmental protest, including the role of social networks for shaping identification with and participation in environmental movements.

Why do people participate in the movement to protect Clayoquot Sound? Responses from members of FOCS reveal an attachment to postmaterialist values, including the belief in the interdependence of the environment and the economy, as well as deep concerns with industrial logging. Members also demonstrate a strong identification with the environmental movement. These are some of the factors that compelled people to join the movement. Clayoquot Sound has been the site of concern for environmentalists and a symbol of wilderness preservation for over 30 years. Environmentalists used visual images of clear-cuts as a key tactic in mobilizing support for a moratorium on logging in Clayquot Sound. In qualitative interviews conducted prior to the survey research reported in this article (in 1993 and 1994), many respondents described the powerful emotional response that these images invoked. For example, one interview respondent commented on the power of images, saying, “... people realize immediately that there is a problem. This type of destruction is not natural, it doesn't mimic natural disturbances and this type of destruction is not going to go away ... if people see a clear-cut and it's emotional for them, especially if they see a forest superimposed with a clear-cut, then that's good..." Other respondents described the importance of Clayoquot Sound as a symbol for wilderness preservation, including one respondent who described it as a unique ecosystem in B.C. that provides "hope for wilderness preservation," pointing to its role as a "feeding ground for orcas and gray whales when they migrate," as well as having "some of the best salmon runs left between Alaska and California."

The rise of the environmental movement over the last 50 years in the Western world is partly explained by a shift from materialist values that emphasize economic growth and security, to postmaterialist values that focus on quality of life, the environment, and democracy (Inglehart 2008). In open-ended survey responses, FOCS members demonstrated a high level of commitment to postmaterialist values. For example, one respondent demonstrated his fears about the consequences of industrial logging in the area by stating, "it is atrocious how many trees on Vancouver Island are cut and shipped out of B.C. We are destroying our heritage, in the end you cannot breathe money, cannot eat money." Another respondent argued that, "preserving wilderness is critical. I am dismayed by the exploitation of natural values under our current provincial government. Economic values have trumped other values. I keep up the struggle and hope younger people will come along to take our place as we age." The opposition to large-scale industrial logging expressed by many of the survey respondents reveals a belief in the importance of the noneconomic value of forests and the concern for future generations.

Other respondents demonstrated a strong commitment to what they believe to be the obligations of democratic citizenship and argued that environmental groups must protect the forests in the absence of governmental regulation. One respondent revealed this commitment when she commented, "those of us who stood on a public bridge accessing public lands did so as a profound expression of the seriousness with which we take the obligations of citizenship." She went on to add, "we responded to a moral imperative ... there is the moral obligation of citizens to respond to situations of this kind when the law does violence to the common good."

Many members of FOCS who strongly identify with the environmental movement and FOCS in particular would likely agree with this woman's statement that FOCS is "an amazing group of people doing amazing things," as well as this man's claim that "they have a marvelous strength of conviction and commitment to their values." Beyond a commitment to the goals of FOCS, many of the respondents also expressed support for more radical tactics, including blockades, destruction of property, and sit-ins, to ensure that logging is stopped in old-growth areas. For example, one respondent claimed that "if it wasn't for protests, boycotts, and demonstrations it would be a free for all of countries ruining our planet. These methods have definitely made a difference." 
Although the members of FOCS consistently expressed support for postmaterialist values as well as fears about job losses and other threats related to overcutting, and strongly identified with the environmental movement, these factors only partially explain why they engaged in environmental activism. The following quantitative network analysis reveals the importance of the association between the extent to which individuals were embedded in movement networks and their likelihood of engaging in ongoing activism.

\section{Intergroup comparisons}

Table 2 provides a comparison between FOCS survey respondents with the Port Alberni general public, the Victoria general public, and countermovement organization members (Share). Percentages, or means, and standard deviations are reported (depending upon the variable).

FOCS respondents were mostly likely to believe that job loss in forestry is due to overcutting; almost a half of respondents mostly or completely agreed with this. Victoria respondents (from a medium-sized urban center) were next most likely to agree with this. Port Alberni residents (from a smaller, industry town) were somewhat less likely to agree with this. Not surprisingly only a small proportion of countermovement organization members agreed with this statement. This relationship is statistically significant (Chi Square $=104.82, \mathrm{df}=12, \mathrm{p}<0.001)$.

FOCS members were much more likely to identify themselves very strongly or strongly with the environmental movement compared to the other three groups. This relationship is statistically significant $($ Chi Square $=385.68, \mathrm{df}=12, \mathrm{p} .<0.001)$.

The four groups are also compared in terms of the priority they give to postmaterialist values. For this scale a low number means that values are given a high priority, and a high number means that these values are given a lower priority. As we would expect from theory, FOCS members give postmaterialist values the highest priority, the countermovement $(\mathrm{CM})$ gives them the lowest priority, and the general public rate these values in between. Again these differences are statistically significant $(\mathrm{F}(3,537)=$ 19.78, p. <0.001).

Although it appears that the factors discussed above differentiate environmental movement organization members from nonmembers, questions remain concerning differences in networks and participation. Table 2 shows that members of FOCS have significantly more ties to other ENGO members $(F[3,567]=$ 16.62 , p. $<0.001)$, and are significantly more active in environmental movement activities $(\mathrm{F}[2,440]=190.74$, p. $<$ 0.001). With regard to the former results, it might be noted that members of the CM actually have more ties than members of the general public. This might seem surprising on the surface, but our qualitative research suggests that these ties are often formed in conflictual situations in interactions between the environmental movement and the countermovement (recall, most people travel through Port Alberni en route to Clayoquot Sound), so it makes sense that CM members have more ties to ENGO members than do members of the general public.

With regard to activism, members of FOCS on average are about twice as active as members of the general public. Here the scale is based on the number of items they participate in, out of 8. (This question was not asked in comparable format for the CM.)

\section{Multivariate analysis explaining level of activism}

Table 3 provides OLS multiple regression analysis results for a model that explains level of participation in environmental movement activities using standardized regression coefficients. Four standard socio-demographic control variables are included: education, income, gender, and age. For the original data, age is the only socio-demographic variable that has a significant effect (younger respondents are more active). For the models with imputed data, there are significant effects for gender (men are more active), and for age (younger respondents are more active). Attitudes toward overcutting have a positive significant effect for the original data, but are not significant for the pooled imputed models. The postmaterialist values index is not significant in either set of models. Thus, we can conclude that while attitudes and values distinguish members of FOCS from other groups (as shown in Table 3), these variables do not explain differential levels of participation within the movement.

Range of ENGO ties has a strong positive and significant effect for both the model using the original data, and the models with imputed data, thus supporting H1. Indeed it has the strongest statistical effect of the explanatory independent variables. Level of identification has a positive, statistically significant effect for the model with the original data, as well as the models with imputed data, thus supporting $\mathrm{H} 2$.

Finally, we control for length of membership with FOCS. This is a necessary additional control variable because we are analyzing cross sectional data, and investigating processes that occur over time (especially with regard to our measure of the dependent variable). For example, the longer one has been part of the movement, the more opportunities there are to participate in activities, and the more opportunities there are to make social network ties. So we need to control for time, to ensure that any correlation between network ties and activism is not simply a function of time spent in the movement. Here, we find that there is indeed a significant positive effect for length of membership. The longer one has belonged to FOCS, the more active one is. This effect is relatively large, positive, and significant both for the model with the original data, and for the models with imputation. However, the effects for range of ENGO ties and level of identification persist even when length of membership is controlled, indicating that the correlations between these variables and activism are not merely spuriously related to time. The $\mathrm{R} 2=0.37$ for the original data, and ranges from 0.331 to 0.370 for the models with imputed data, a relatively large amount of explained variation in the dependent variable by typical social science standards.

In sum, although values and attitudes distinguish members of this environmental organization from members of the general public and a countermovement organization (as shown in Table 2), they do not statistically explain differential participation in ongoing activism amongst FOCS members. Rather, these are better explained statistically by one's range of ties to people in different environmental organizations, and by one's level of identification with the movement (as shown in Table 3).

\section{Bivariate results: network mechanisms}

Table 4 shows the results of intercorrelations between the two main explanatory variables (range of ENGO ties, level of identification), the dependent variable (level of activism), with 
two variables that are indicators of interpersonal interaction: (1) frequency of communication about environmental issues, and (2) frequency that the respondent receives requests to participate in movement activities. Table 4 shows that communication and recruitment are significantly and positively correlated with all of the variables listed above. People with a greater range of ENGO ties talked more frequently with others about environmental issues, and were more likely to receive requests to participate in movement activities. People who talked more with others about environmental issues, identified more strongly with the environmental movement, and were more active. People who more frequently received requests to participate in movement activities identified more strongly with the movement, and were more active. Because we are utilizing a cross-sectional design we cannot prove causality. However, these results are consistent with the idea that interpersonal interactions in the form of more frequently talking about environmental issues, and being more likely to receive a request to participate are two of the mechanisms that underlie the correlation between range of ENGO ties and level of activism.

\section{DISCUSSION}

A central objective of this study has been to introduce and test a model of the relationship between ego-network centrality and environmental activism in the important case of mobilizing to protect the ancient rainforests of Clayoquot Sound. Although we focus on the factors associated with micromobilization, activism in the Clayoquot case seemingly played an important role in the subsequent management of this area because there has not been significant industrial-scale logging activities since the original mobilization, in part, because of subsequent actions that were taken by various governing bodies, pointing to the importance of social movements for shaping policy outcomes (Amenta et al. 2010).

The findings from this study are consistent with a theoretical argument about the relationship between ego-networks and social movement participation. The 1993 protests over Clayoquot Sound marked the most highly visible environmental mobilization in Canadian history. This study is the first to provide a quantitative analysis, statistically explaining low-medium cost environmental activism associated with ongoing efforts to protect Clayoquot Sound in the period subsequent to the 1993 mobilization. Most research on social networks and natural resource management focuses on governance processes and the role of social networks for mitigating conflict in decision making. Although this area of investigation is critically important for understanding environmental conflict, our research focuses on a less studied dimension of environmental conflict: the relationship between personal networks and participation in environmental protest. In the context of our analysis, we contrasted structural (networks) and ideational factors (values and attitudes). We argue that although values and attitudes about environmental issues play some role in shaping who gets involved, structural factors are statistically more important for explaining the ongoing activism of individuals.

This study is primarily situated within the social networks and social movements literature. However, as we noted earlier, and as evidenced by other works in this journal, there is a substantial and growing literature on the contributions of social network analysis to environmental governance (see for example: Ernstson et al. 2010, Bodin and Prell 2011, Bodin et al. 2011). At the same time, social movement scholars have increasingly sought to understand the outcomes of social movements (Giugni 1998). Our study suggests that a potentially fruitful future research endeavor might be to bring these two types of literature together, to understand how networks and social movement mobilization are related to resulting networks of environmental governance. For, example, Diani (1997) and Tindall et al. (2012) discuss network social capital (to people and groups outside of the movement) that arises out of protest and mobilization. Is this new social capital reconstituted in environmental governance arrangements?

Earlier we discussed several challenges involved in this type of research. One is the issue of sampling on the dependent variable. To overcome this, we collected data on several nonmovement populations and compared them with the environmental movement. As theory would suggest, members of the movement had significantly more ties to other movement participants, and were significantly more active than members of the general public. This is an important contribution of the current research because this type of comparison in research on networks and social movements is extremely rare.

A theoretical implication of our regression findings is suggested in the contrast between values and attitudes and social network effects. These results provide some evidence that the effects reported here are not merely a function of social selection, that is, the notion that people who are more concerned about environmental issues have more ties to others, and are more active (and thus any correlation between networks and activism is spurious). We found that even when values and attitudes were statistically controlled, there was a significant, positive net association between network centrality and level of activism. Thus, although we cannot fully separate potential social influence from social selection effects, it is not the case that the relationship between network centrality and ongoing activism is simply a result of pre-existing values and attitudes. These insights also apply to identity. It is not the case that the relationship between networks and ongoing activism is spurious because of the fact that they are both correlated with level of identification, as the effect persists even when identification is statistically controlled.

It is likely the case that values and attitudes play a role in who gets involved with the movement (as reported earlier by Tindall 2002 with regard to another study on mobilization for environmental protection on Vancouver Island), but our findings suggest that once a person becomes a member of an ENGO such as FOCS then their ongoing activism in the movement is better statistically explained by factors such as their network embeddedness into the movement, and their identification in the movement. These findings provide additional insight in understanding mobilization in this particular case, the ongoing struggle to preserve the ancient temperate rainforests of Clayoquot Sound.

The above said, there is also a literature on the relationship of social networks to values, attitudes, and opinions (see Erickson 1982, 1988). Thus, although our analysis provides evidence of independent statistical effects of network centrality on environmental activism, net of values, and attitudes, it may be 
that even the effects of values and attitudes (such as demonstrated by the differences between members of FOCS and the comparison groups studied here) have a network component. Examining the network basis of values and attitudes, however, is beyond the scope of our paper.

A few additional words might also be said about identity. Collective identity has long been an important concept in the social movements literature. Resource mobilization theorists see it as a necessary condition for mobilization to occur. New social movement theorists see it as an important outcome of social movement processes. In this study we empirically demonstrate its relationship with both network embeddedness, and ongoing activism. We have also discussed some of the network and social psychological processes that underlie these relationships (such as social comparison). The salience of collective identification varies with the intensity of the wave of protest (Tindall 2004). If our data collection had occurred at a different point in time, the statistical effects for level of identification might have been different, e.g., even stronger during an intense period of protest. Similarly, we can theorize network ties as being relatively more manifest or latent at different points in time. Future research might consider the dynamics of these variables over time. Nevertheless, we have demonstrated, through our quantitative analysis, that identification is an important correlate of participation. This also suggests that collective identification might be given greater attention in future work on ecological governance because it is one of the key dimensions of community (Wellman 1979), and it is a strong statistical predictor of collective action.

\section{Limitations}

The main limitation of the current study is the fact that crosssectional data are used. As discussed above, we cannot completely distinguish between social selection effects and social influence effects. Relatedly, our findings can only be considered correlational and not causal.

Nevertheless, the correlational results concerning network centrality, identification, and ongoing activism are consistent with our theoretical predictions. But to fully distinguish influence from selection we would need to have longitudinal panel data, and conduct a SIENA analysis (Snijders et al. 2010) or a similar approach. This is a very difficult task in many interesting real world settings. Second, although the comparison data we have is quite novel, the data for this study were quite difficult to obtain partly because of issues of obtaining access, and partly because of the necessity of obtaining timely funding. In particular, data collection for FOCS members was delayed. It should be noted that the time period of data collection for these several studies was a period of declining environmental protest in British Columbia. Thus, we believe it is likely that the time gaps in data collection between FOCS and the other groups likely lead to the underestimation of differences between FOCS and the other groups, and thus our findings are likely somewhat conservative. However, logically, we cannot rule out the possibility that observed differences are due to data being collected at different times. This potential weakness, however, does not apply to the main finding regarding the relationship between network centrality and ongoing activism among members of FOCS.

\section{Avenues for future research}

In the present analysis we have not distinguished between strong and weak ties (Granovetter 1973, McAdam 1986), a distinction that could be explored further for this case. Past research (Tindall 2002) has suggested that weak ties may be more important for low-medium cost activism (such as measured here), while other research (McAdam 1986) suggests strong ties may be more important for explaining participation in higher risk activities (such as participation in civil disobedience and direct action).

This study has not focused on tie/network formation, including networks/ties as an outcome, or dependent variable. Feld (1981) has suggested that various institutions and organizations can serve as foci for tie development. Such foci are also important in producing homophily effects (McPherson and Smith-Lovin 1987). It would be interesting to explore these issues for this particular case. Indeed, future research should explore the question of why it is that British Columbia apparently has the most vibrant environmental movement in Canada (Tindall et al. 2015).

In this study we have examined network centrality and its correlation with ongoing activism in general. Future research might examine the networks of particular key actors, using a more in-depth approach to understand the specific dynamics of individual ties and participation in social movements, including over time. Indeed, a number of the key activists who organized the original Clayoquot protests have gone on to be involved in other organizations, and are now key actors in mobilizations to battle the expansion of petroleum infrastructures in North America such as the Northern Gateway Pipeline, the Transmountain Pipeline, and the Keystone XL Pipeline (Saxifrage et al. 2012) as part of the environmental movement effort to combat anthropogenic climate change (Klein 2014). Indeed, there was a major protest in Burnaby (in Greater Vancouver) in 2014 called Clayoquot Day, where prominent activists from the Clayoquot campaign engaged in civil disobedience, and were arrested by police (The Canadian Press 2014)

The Clayoquot protest set the stage for the proliferation of a robust environmental movement in British Columbia and for the formation of unique partnerships, including coalitions with indigenous groups that emerged to ensure sustainable forest practices on Vancouver Island and beyond. The spillover to other campaigns suggests that network embeddedness also impacts future activism, as supported by research that identifies social networks, social capital, and movement communities as key outcomes of social movements (Diani 1997, Staggenborg and Lecomte 2009, Robinson 2013), as noted above.

It would be interesting for researchers to examine the lessons learned by these activists from the earlier protests, and see how they are being applied to these new campaigns. Further, although we distinguish the broader focus of social network analysis from analysis of social media, a number of the leaders of the Clayoquot protests have become significant nodes in social media networks. An elaboration of the approach undertaken here might also examine the linkages between online and offline social networks, and the roles that these leaders play in both sectors. 
Responses to this article can be read online at: http://www.ecologyandsociety.org/issues/responses. php/9042

\section{Acknowledgments:}

This project involved a large number of different components. We would like to express our gratitude to the organizations and individuals who assisted us in various ways. First we would like to thank the members/supporters of the Friends of Clayoquot Sound for their participation. We would also like to thank the members/ supporters of Share Our Resources of Port Alberni, and members of the general public in Victoria and Port Alberni. Thanks to Theresa Negreiff Bullock for facilitating the survey of FOCS members, and to Carol Lundy for facilitating the survey of Share members. We would also like to thank the following people who served as research assistants on this project: Kamaljit Inman-Bates, Céline Mauboulès, Chantelle Marlor, Gabrielle Pechlaner, Dan Kruk, Emily MacNair, Melanie Brown, Andrea Rivers, Todd Malinick, and Mark Stoddart. This research was supported through several research grants from the Social Sciences and Humanities Research Council of Canada, and several internal grants from the UBC-HSS Fund.

\section{LITERATURE CITED}

Amenta, E., N. Caren, E. Chiarello, and Y. Su. 2010. The political consequences of social movements. Annual Review of Sociology 36:287-307. http://dx.doi.org/10.1146/annurev-soc-070308-120029

Andrews, K., and B. Edwards. 2005. The organizational structure of local environmentalism. Mobilization: An International Quarterly 10(2):213-234.

Babbie, E., and L. Benaquisto. 2010. Fundamentals of social research. Second Canadian edition. Nelson Education, Toronto, Ontario, Canada.

Baldrey, K. 1993. Public backs Clayoquot logging plan. Vancouver Sun, 3 November.

Belaire, J. A., A. K. Dribin, D. P. Johnston, D. J. Lynch, and E. S. Minor. 2011. Mapping stewardship networks in urban ecosystems. Conservation Letters 4:464-473. http://dx.doi. org/10.1111/j.1755-263X.2011.00200.X

Bem, D. J. 1972. Self-perception theory. Pages 1-62 in L. Berkowitz, editor. Advances in experimental social psychology. Vol. 6. Academic Press, New York, New York, USA. http://dx. doi.org/10.1016/s0065-2601(08)60024-6

Berman, T., and M. Leiren-Young. 2011. This crazy time: living our environmental challenge. Knopf Canada, Toronto, Ontario, Canada.

Bodin, Ö., and C. Prell, editors. 2011. Social networks and natural resource management: uncovering the social fabric of environmental governance. Cambridge University Press, Cambridge, UK. http:// dx.doi.org/10.1017/cbo9780511894985

Bodin, Ö., S. Ramirez-Sanchez, H. Ernstson, and C. Prell. 2011. A social relational approach to natural resource governance. Pages 3-28 in Ö. Bodin and C. Prell, editors. Social networks and natural resource management: uncovering the social fabric of environmental governance. Cambridge University Press, Cambridge, UK. http://dx.doi.org/10.1017/cbo9780511894985.002

Braun, B. 2002. The intemperate rainforest: nature, culture and power on Canada's West Coast. University of Minnesota Press, Minneapolis, Minnesota, USA.

Carlsson, L., and F. Berkes. 2005. Co-management: concepts and methodological implications. Journal of Environmental Management 75:65-76. http://dx.doi.org/10.1016/j.jenvman.2004.11.008

Carmines, E. G., and R. A. Zeller. 1979. Reliability and validity assessment. SAGE, Thousand Oaks, California, USA. http://dx. doi.org/10.4135/9781412985642

Cashore, B., I. Vertinsky, and R. Raizada. 2000. Firms' responses to external pressures for sustainable forest management in British Columbia and the U.S. Pacific Northwest. Pages 80-120 in D. J. Salazar and D. K. Alper, editors. Sustaining the forests of the Pacific Coast: forging truces in the war in the woods. University of British Columbia Press, Vancouver, British Columbia, Canada.

Diani, M. 1997. Social movements and social capital: a network perspective on movement outcomes. Mobilization 2(2):129-147.

Diani, M., and D. McAdam, editors. 2003. Social movements and networks relational approaches to collective action. Oxford University Press, New York, New York, USA.

Dunlap, R. E. 1992. Trends in public opinion toward environmental issues; 1965-1990. Pages 89-116 in R. E. Dunlap and A. G Mertig, editors. American environmentalism: the U.S. environmental movement, 1970-1990. Taylor and Francis, Philadelphia, Pennsylvania, USA.

Erickson, B. H. 1982. Networks, ideologies, and belief systems. Pages 159-72 in P. Marsden and N. Lin, editors. Social structure and network analysis SAGE, Thousand Oaks, California, USA.

Erickson, B. H. 1988 The relational basis of attitudes. Pages 99-121 in B. Wellman and S. D. Berkowitz, editors. Social structures: a network approach Cambridge University Press, Cambridge, UK.

Ernstson, H., S. Barthel, E. Andersson, and S. T. Borgström. 2010. Scale-crossing brokers and network governance of urban ecosystem services: the case of Stockholm. Ecology and Society 15(4):28. http://dx.doi.org/10.5751/es-03692-150428

Feld, S. L. 1981. The focused organization of social ties. American Journal of Sociology 86(5):1015-1035. http://dx.doi.org/10.1086/227352

Fox, J. 1997. Applied regression analysis, linear models, and related methods. SAGE, Thousand Oaks, California, USA.

Fisher, D. R., L. K. Campbell, and E. S. Svendsen. 2012. The organisational structure of urban environmental stewardship. Environmental Politics 21(1):26-48. http://dx.doi. org/10.1080/09644016.2011.643367

Friedkin, N. E. 2006. A structural theory of social influence. Vol. 13. Cambridge University Press, Cambridge, UK. http://dx.doi. org/10.1017/cbo9780511527524

Gartrell, C. D. 1987. Network approaches to social evaluation. Annual Review of Sociology 13:49-66. http://dx.doi.org/10.1146/ annurev.so.13.080187.000405 
Giugni, M. G. 1998. Was it worth the effort? The outcomes and consequences of social movements. Annual Review of Sociology 24:371-393. http://dx.doi.org/10.1146/annurev.soc.24.1.371

Gould, R. V. 2003. Why do networks matter: rationalist and structuralist interpretations. Pages 233-257 in M. Diani and D. McAdam, editors. Social movements and networks: relational approaches to collective action. Oxford University Press, New York, New York, USA. http://dx.doi.org/10.1093/0199251789.003.0010

Granovetter, M. S. 1973. The strength of weak ties. American Journal of Sociology 78:1360-1380. http://dx.doi.org/10.1086/225469

Groves, R. M. 2006. Nonresponse rates and nonresponse bias in household surveys. Public Opinion Quarterly 70(5):646-675.

Heaney, M. T., and F. Rojas. 2008. Coalition dissolution, mobilization, and network dynamics in the US antiwar movement. Pages 39-82 in P. G. Coy, editor. Research in social movements, conflicts and change Volume 28. Emerald Group Publishing, Bingley, UK. http://dx.doi.org/10.1016/S0163-786X (08)28002-X

IBM Corp. 2016. IBM SPSS Statistics for Windows, Version 24. IBM Corp, Armonk, New York, USA.

IBM Software Group. 2016. IBM SPSS Missing Values 24. IBM Software Group, Chicago, Illinois, USA.

Inglehart, R. 1977. The silent revolution: changing values and political styles among Western publics. Princeton University Press, Princeton, New Jersey, USA. http://dx.doi.org/10.1515/9781400869589

Inglehart, R. F. 2008. Changing values among Western publics from 1970 to 2006. West European Politics 31(1-2):130-146. http:// dx.doi.org/10.1080/01402380701834747

Kim, J.-O., and C. W. Mueller. 1978. Factor analysis: statistical methods and practical issues. SAGE, Thousand Oaks, California, USA. http://dx.doi.org/10.4135/9781412984256

Kitts, J. A. 2000. Mobilizing in black boxes: social networks and participation in social movement organizations. Mobilization 5:241-257.

Klandermans, B. 2004. The demand and supply of participation: social-psychological correlates of participation in social movements. Pages 360-379 in D. A. Snow, S. A. Soule, and H. Kriesi, editors. The Blackwell companion to social movements. Blackwell, Oxford, UK. http://dx.doi.org/10.1002/9780470999103. $\underline{\operatorname{ch} 16}$

Klandermans, B., and D. Oegema. 1987. Potentials, networks, motivations, and barriers: steps towards participation in social movements. American Sociological Review 52:519-531. http://dx. doi.org/10.2307/2095297

Klein, N. 2014. This changes everything: capitalism vs. the climate. Simon and Schuster, Toronto, Ontario, Canada.

Knoke, D., and S. Yang. 2008. Social network analysis. Second edition. SAGE, Thousand Oaks, California, USA. http://dx.doi. org/10.4135/9781412985864

Mabee, H., D. B. Tindall, G. Hoberg, and J. P. Gladu. 2013. Comanagement of forest lands. The cases of Clayoquot Sound, and Gwaii Haanas. Pages 242-259 in D. B. Tindall, R. L. Trosper, and
P. Perreault, editors. Aboriginal peoples and forest lands in Canada. University of British Columbia Press, Vancouver, British Columbia, Canada.

Magnusson, W. and K. Shaw. 2002. A political space: reading the global through Clayoquot Sound. McGill-Queen's University Press, Montréal, Québec, Canada.

Malinick, T. E., D. B. Tindall, and M. Diani. 2013. Network centrality and social movement media coverage: a two-mode network analytic approach. Social Networks 35:149-158 http://dx. doi.org/10.1016/j.socnet.2011.10.005

Marsden, P. V. 2011. Survey methods for network data. Pages 370-388 in J. Scott and P. J. Carrington, editors. The SAGE handbook of social network analysis. SAGE, Thousand Oaks, California, USA. http://dx.doi.org/10.4135/9781446294413.n25

McAdam, D. 1986. Recruitment to high-risk activism: the case of Freedom Summer. American Journal of Sociology 92:64-90. http://dx.doi.org/10.1086/228463

McAdam, D., J. McCarthy, and M. Zald. 1988. Social movements. Pages 695-737 in N. J. Smelser, editor. Handbook of sociology. SAGE, Newbury Park, California, USA.

McAdam, D., and R. Paulsen. 1993. Specifying the relationship between social ties and activism. American Journal of Sociology 99:640-667. http://dx.doi.org/10.1086/230319

McAdam, D., and D. Rucht. 1993. The cross-national diffusion of movement ideas. Annals of the American Academy of Political and Social Science 528(1):56-74. http://dx.doi.org/10.1177/0002$\underline{716293528001005}$

McPherson, J. M., and L. Smith-Lovin. 1987. Homophily in voluntary organizations: status distance and the composition of face-to-face groups. American Sociological Review 52:370-379. http://dx.doi.org/10.2307/2095356

Mische, A. 2008. Partisan publics: communication and contention across Brazilian youth activist networks. Princeton University Press, Princeton, New Jersey, USA. http://dx.doi. org/10.1515/9781400830817

Moore, D. L., and J. Tarnai. 2002. Evaluating nonresponse error in mail surveys. Pages 213-228 in R. M Groves, D. A. Dillman, J. L. Eltinge, and R. J. A. Little, editors. Survey nonresponse. John Wiley and Sons, New York, New York, USA.

Nash, R. 2014. Wilderness and the American mind. Yale University Press, New Haven, Connecticut, USA.

Nepstad, S., and C. Smith. 1999. Rethinking recruitment to highrisk/cost activism: the case of Nicaragua exchange. Mobilization $4(1): 25-40$

Opp, K.-D. 1986. Soft incentives and collective action: participation in the anti-nuclear movement. British Journal of Political Science 16:87-112. http://dx.doi.org/10.1017/S0007123400003811

Page, J. 2014. Tracking the Great Bear: how environmentalists recreated British Columbia's coastal rainforest. University of British Columbia Press, Vancouver, British Columbia, Canada.

Passy, F. 2001. Socialization, connection, and the structure/ agency gap: a specification of the impact of networks on participation in social movements. Mobilization 6:173-192. 
Pechlaner, G., and D. B. Tindall. 2013. Changing contexts: environmentalism, aboriginal community and forest company joint ventures, and the formation of Iisaak. Pages 260-278 in D. B. Tindall, R. L. Trosper, and P. Perreault, editors. Aboriginal peoples and forest lands in Canada. University of British Columbia Press, Vancouver, British Columbia, Canada.

Robinson, J. 2013. Contested water: the struggle against water privatization in the United States and Canada. MIT Press, Cambridge, Massachusetts, USA.

Robinson, J. L., D. B. Tindall, E. Seldat, and G. Pechlaner. 2007. Support for First Nations' land claims amongst members of the wilderness preservation movement: the potential for an environmental justice movement in British Columbia. Local Environment 12(6):579-598. http://dx.doi.org/10.1080/13549830701657307

Saxifrage, C., Vancouver Observer, L. Solomon, editors. 2012. Extract: the pipeline wars Vol. 1 Enbridge. Vancouver Observer, Vancouver, British Columbia, Canada.

Shaw, K. 2002. Encountering Clayoquot. Pages 25-66 in W. Magnusson and K. Shaw, editors. A political space: reading the global through Clayoquot Sound. McGill-Queen's University Press, Montréal, Québec, Canada.

Snijders, T. A. B., G. G. van de Bunt, and C. E. G. Steglich. 2010. Introduction to stochastic actor-based models for network dynamics. Social Networks 32:44-60. http://dx.doi.org/10.1016/j. socnet.2009.02.004

Snow, D. A., and D. McAdam. 2000. Identity work processes in the context of social movements: clarifying the identity/ movement nexus. Pages 41-67 in S. Stryker, T. J. Owens, and R. W. White, editors. Self, identity, and social movements. University of Minnesota Press, Minneapolis, Minnesota, USA.

Staggenborg, S., and J. Lecomte. 2009. Social movement campaigns: mobilization and outcomes in the Montreal women's movement community. Mobilization 14(2):163-180.

The Canadian Press. 2014. Clayoquot sound activists arrested at B.C. anti-pipeline protest site. Vancouver Sun, 26 November. [online] URL: http://www.vancouversun.com/Clayoquot+Sound+ activists+arrested+anti+ pipeline+ protest+site/10417004/story.html

Tindall, D. B. 2002. Social networks, identification and participation in an environmental movement: low-medium cost activism within the British Columbia wilderness preservation movement. Canadian Review of Sociology and Anthropology 39 (4):413-452. http://dx.doi.org/10.1111/j.1755-618x.2002.tb00628. $\underline{\mathrm{x}}$

Tindall, D. B. 2004. Social movement participation over time: an ego-network approach to micro-mobilization. Sociological Focus 37(2):163-184. http://dx.doi.org/10.1080/00380237.2004.10571240

Tindall, D. 2013. Twenty years after the protest, what we learned from Clayoquot Sound. Globe and Mail, 12 August. [online] URL: http://www.theglobeandmail.com/opinion/twenty-years-after-theprotest-what-we-learned-from-clayoquot-sound/article13709014/? page $=$ all
Tindall, D. B. 2015. Networks as constraints and opportunities. Pages 231-245 in D. della Porta and M. Diani, editors. Oxford handbook of social movements. Oxford University Press, Oxford, UK.

Tindall, D. B., J. Cormier, and M. Diani. 2012. Network social capital as an outcome of social movement mobilization: using the position generator as an indicator of social network diversity. Social Networks 34:387-395. http://dx.doi.org/10.1016/j. socnet.2011.12.007

Tindall, D. B., J. L Robinson, and M. C. J. Stoddart. 2014. Social network centrality, movement identification, and the participation of individuals in a social movement: the case of the Canadian environmental movement. Pages 407-423 in $\mathrm{M}$. Dehmer and F. Emmert-Streib, editors. Quantitative graph theory: mathematical foundations and applications. Chapman and Hall/ CRC, Oxford, UK.

Tindall, D. B., J. L. Robinson, and M. C. J. Stoddart. 2015. A view from sociology: environmental movement mobilisation over old-growth temperate rainforests in British Columbia. Pages 152-167 in S. M. Redpath, R. J. Gutiérrez, K. A. Wood, and J. C. Young, editors. Conservation conflicts: navigating towards solutions. Cambridge University Press, Cambridge, UK. http:// dx.doi.org/10.1017/cbo9781139084574.012

Wasserman, S., and K. Faust. 1994. Social network analysis: methods and applications. Cambridge University Press, Cambridge, UK. http://dx.doi.org/10.1017/cbo9780511815478

Wellman, B. 1979. The community question: the intimate networks of East Yorkers. American Journal of Sociology 84:1201-31. http://dx.doi.org/10.1086/226906

Wilson, J. 1998. Talk and log: wilderness politics in British Columbia. University of British Columbia Press, Vancouver, British Columbia, Canada. 